\title{
Divergencias. Trayectorias del neoliberalismo en Argentina y Chile. Tomás Undurraga
}

\author{
Ediciones Universidad Diego Portales.Santiago, Chile, \\ 2014, 360 págs.
}

\author{
Raimundo Frei Toledo \\ UNDP, Santiago, Chile. \\ Email: raimundo.frei@gmail.com
}

Sería difícil pensar una separación más natural y clara entre dos países que estar divididos por una franja cordillerana. En el tratado de 1881, los gobiernos de Chile y Argentina concordaban que su frontera transcurría por las cumbres más elevadas de la Cordillera de los Andes. Sin embargo, a veces pareciera que esos límites, natural y político, fundaran a la vez una frontera simbólica, incluso más irremontable que aquellas. Como si la cordillera hubiese incapacitado a sus habitantes de traspasar ciertas fronteras imaginarias, de lado a lado, y mostrarnos faltos de análisis que tomen en serio nuestras similitudes y diferencias, en términos económicos, políticos, y culturales. En vez de eso, nuestros medios de comunicación, y buena parte de nuestras ciencias sociales y políticas, se alimentan de los mitos nacionales que circulan entre ambos países. El país del orden y el progreso frente al país del caos y la decadencia, o su narración opuesta, el país desigual y neoliberal frente al país de la igualdad y de los bienes públicos. El libro de Tomás Undurraga atraviesa esa cordillera simbólica que nos distancia y ofrece una exhaustiva comparación de los distintos caminos que han tomado ambas sociedades en los últimos cuarenta años. Es una obra, en primer lugar, desmitologizante que quiebra una fuerte inercia de nacionalismo metodológico que impera en ambas comunidades sociológicas.

El libro comienza con una arriesgada promesa: un análisis histórico y comparativo de los 'tipos de capitalismo', envolviendo con ello no solamente la examinación de los marcos institucionales y las posiciones de fuerza que ocupan actores económicos y políticos, sino también los sistemas de prácticas que organizan ambos mercados así como sus justificaciones -o como el autor señala en un revival de la sociología de la religión weberiana- los espíritus que informan ambos capitalismos. La apuesta del libro -y evidentemente su riesgo- es la pretensión de ofrecer una exhaustiva comparación que involucre tanto elementos institucionales, como los juegos prácticos de poder, así como los órdenes de justificación del capitalismo chileno y argentino. Éste último elemento -que sería el objeto propio de una sociología cultural- que a veces se llama 'espíritu', otras 'reperto- 
rios de evaluación’, se pensaría a partir de los ‘circuitos culturales del capitalismo’ (centros de estudios, universidades, prensa, entre otros) que legitiman las reglas institucionales y los saberes prácticos de grupos políticos y empresariales a la hora de incrustar (o resistir) el capitalismo global en los mercados del cono sur.

El riesgo de esta promesa es su excesiva pretensión y el lector debiese no esperar ver saciada las expectativas levantadas por semejante propuesta introductoria. Pero la obra es consistente en guiar al lector en ambas trayectorias nacionales, en la cual actores económicos van definiendo y desarmando reglas, enfrentándose y resistiendo crisis, inflaciones, movimientos sociales y diferentes proyectos políticos. Tanto el lector chileno como argentino verán en la historia del otro país las semejanzas y diferencias de ambas dictaduras, el proceso de neoliberalización del mercado en los ochenta (más marcado en Chile a esa época) y en los noventa (más marcado en Argentina a esa época), así como las divergencias que se han producido en respuesta a las crisis políticas y económicas de las últimas décadas. Así, Tomás Undurraga incursiona en las diferencias de la Argentina de los Kirchner (mostrando especialmente los méritos del primer gobierno de Néstor Kirchner) así como en las causas que subyacen a las movilizaciones estudiantiles entre el 2006-2011 (con ello enfocando más la mirada en el gobierno de Sebastián Piñera que en el primer gobierno de Michelle Bachelet). Las divergencias en ambas formas gubernamentales del 2003-2011 asoman de este modo como el punto de mayor interés: finalmente ambos países con fuertes encausamientos neoliberales tuvieron trayectorias diferentes(aquí el lector puede recordar que Argentina también fue un país de importantes políticas neoliberales y no sólo Chile es la 'cuna del neoliberalismo' latinoamericano). Y en este sentido, como toda gran obra sociológica, el valor reside aquí, más allá de las respuestas que el autor ofrece, en colocar la pregunta adecuada: ¿por qué difirieron ambas trayectorias de neoliberalismo?

La obra de este sociólogo chileno se inscribe en la literatura de las variedades del capitalismo. Sin embargo, hay un especial interés en entrecruzar teóricamente los aspectos más institucionalistas de esta perspectiva con una perspectiva más 'cultural', a través de la revisión del concepto de “espíritus del capitalismo” (desde Max Weber, pasando por Joseph Schumpeter hasta la obra de Luc Bolstanki y Eve Chiapello). Este entrecruzamiento es reforzado por el fructífero concepto de "repertorios de evaluación” (Michelle Lamont y Laurent Thévenot)y la noción de “circuitos culturales del capitalismo" (Nigel Thrift). Pese a ello, una de las debilidades del texto es que conceptualmente no es consistente al definir las relaciones entre institución y cultura, en parte por la gran cantidad de términos que se utilizan para definir ésta última (espíritu, repertorios, creencias, discursos, retorica). Incluso, la propia definición de espíritu como “ideología que promueve la adopción de un modelo” (pp. 33, y pp.65) introduce un nuevo elemento ('ideología’) que conlleva a la vez una diferente tradición crítica que no se discute en el texto. 
Metodológicamente, la investigación de las distintas variedades del capitalismo no debe basarse sólo, el autor argumenta, en los textos que inspiran a los actores (al estilo de Weber o Bolstanki y Chiapello) sino investigar sus prácticas y estrategias. En este sentido, para llevar a cabo su estudio,Tomás Undurraga entrevistó a 120 personajes de la eliteeconómica, política, intelectual de Chile y Argentina. Esto fue acompañado de una exhaustiva revisión bibliográfica, análisis de prensa y etnografías en algunos de los 'circuitos del capitalismo'. Ahora bien, el texto no pretende ser una 'historia de la época' sino una reconstrucción de los repertorios de los actores. Sin embargo, en el desarrollo del texto la utilización de las entrevistas es relativamente baja y asoma con mayor claridad el análisis de la literatura de la época. En este sentido, Tomás Undurraga avanza en un diseño cualitativo extenso en la etapa del 'campo' (la muestra de entrevistas), pero quizás faltó una metodología de análisis propiamente tal para la lectura de las entrevistas (análisis de discurso, narrativo, argumental, entre otras opciones).

En éste último sentido, la mayor parte del texto (desde el capítulo 4 hasta el 12) aborda una historia comparada de las estrategias que actores políticos y económicos desplegaron en ambos países para llevar a cabo reformas de mercado (la emergencia del neoliberalismo) o su resistencia (el capitalismo nacional popular de Kirchner y la resistencia de la sociedad civil en Chile). Estos capítulos son de factouna revisión bibliográfica y una productiva discusión en los ámbitos de la política y la economía. Por ello, el trabajo de Undurraga debe colocarse al lado de los trabajos recientes realizados por Marcos Novaro en Argentina y por Manuel Gárate en Chile para establecer un completo panorama de la historia política, económica y cultural de los últimos cuarenta años. La gracia del texto es superar el simplismo en que a veces nos sumerge la ciencia política comparada, con sus cifras y modelos, para dar pie a una revisión de las disputas, contingencias y prácticas sedimentadas de las elites económicas y políticas que llevaron a que ambos capitalismos difieran en sus rutas. La literatura de variedades del capitalismo gana aquí narratividad.

Antes que detenerme en la prosecución de eventos, posicionamiento de actores y estrategias que Tomás Undurraga identifica, quisiera realzar la diferencia entre ambas elites económicas (demostrando un hecho básico, pero a veces olvidado a merced del capitalismo global, que las elites económicas nacionales pueden operar de distinta manera; ver de partida el excelente recuadro de la página 203). A lo largo de la parte IV, el sociólogo chileno demuestra como la elite chilena posee una fuerte unidad de grupo, afianzada por un repertorio neoliberal en lo económico, una justificación religiosa (elneoconversadurismo católico transmitido por grupos como el Opus Dei y los legionarios de Cristo), así como una afianzada red de centros en que su posición hegemónica se legitima (Centro de Estudios Públicos, el diario El Mercurio, Icare). Esto contrasta con la fragmentación de la comunidad empresarial argentina. Atravesada por múltiples crisis (desde la crisis del 83, la hiperinflación del 89, y el colapso del 2001), la elite económica argentina parece ser más adaptativa que hegemónica a la hora de cumplir su 
rol de elite. Al relacionarse con el Estado y el mundo político (y esto significa, primordialmente, con el peronismo), los empresarios argentinosvelan por su propia suerte (y esto es con un sentido de oportunidad más que ideológicamente alineados), capturando los espacios de transacción informal que el estado 'prebendario' ofrece (tanto en la época de Menem como en la época de Kirchner). Por otro lado, los centros de legitimación de las reformas liberales nunca llegaron a tener peso en Argentina (ni en universidades ni centro de estudios, especialmente después de la crisis de la convertibilidad), y siempre floreció una corriente de intelectuales crítica a las reformas liberales. Como consecuencia, no sólo el empresariado argentino no poseería la capacidad de unidad e influencia sobre el poder político como en el caso chileno, sino que también desarrollaron diferentes sistemas de prácticas. Undurraga señala: "mientras los managers argentinos destacan por una alta capacidad de adaptación y negociación para enfrentar ambientes conflictivos, sus colegas chilenos son reconocidos por ser propensos a la planificación, por su estilo vertical y por su fascinación con las herramientas cuantitativas" (pp. 204).

Una de las claves que está en juego en la comparación de ambos capitalismos es la idea de jerarquía. Ya la literatura sobre variedades de capitalismo aplicada a los casoslatinoamericanos ha hecho suyo la idea de que estos países poseen un patrón común llamado "economías de mercados jerárquicos" (ver especialmente los trabajos de Ben Ross Schneider). Dado esto Undurraga pudiese haber perseguido con mayor sistematicidad cual es la idea de jerarquía en ambos países. Pareciera en un primer momento que Chile fuese un caso ideal de un "modelo jerárquico de sociedad": relaciones laborales atomatizadas, mano de obra poco calificada, consorcios económicos a manos de grupos familiares, sumado al poder de empresas multinacionales. Eso se refleja también en las relaciones entre empresarios y trabajadores, pasando por la baja sindicalización (históricamente determinada por las prácticas de represión durante la dictadura). Ahora bien, la noción de jerarquía queda más difusa en el caso argentino. Si bien el poder de sindicatos y su sociedad civil permite que se establezcan relaciones más igualitarias - favorecidos por la baja legitimidad e incumplimiento que tienen ciertos procesos regulatorios (léase clientelismo, corrupción, cooptación) - queda al debe una reflexión sobre la jerarquía y la autoridad en el caso argentino. El autor dice: "las relaciones laborales son más jerárquicas en Chile, mientras que en Argentina los trabajadores tienden a desafiar, antes que mostrar deferencia frente a la autoridad. Pero habría que recordar el texto de Guillermo O’Donnell ¿YY a mí que me importa? donde se señalaba precisamente que el 'corporativismo anárquico' argentino escondía en parte una profunda desigualdad social. En ese texto O’Donnell afirmaba: "igualitario e individualista no es igual a democrático, y mandar a la mierda a quien invoca la jerarquía social es ratificarla (aunque sembrando odios), no superarla o disolverla” (Guillermo O’Donnell, “¿Y a mí que me importa?”, 1984:16).

Existe un cierto fantasma que recorre el texto de Undurraga: Chile un país jerárquico, desigual y neoliberal frente a una Argentina pos-crisis que 
a través del gobierno de los Kirchner desafió las estrategias de liberalización a ultranza llevadas a cabo por Menem de la mano del FMI y el Banco Mundial. El texto gana cuando esa narrativa de blancos y negros (que no deja de predominar en varias instancias, véase pp. 137, 139, 155) pasa a una lectura más compleja y crítica del caso argentino. No hay que olvidar las redes clientelares, el neo-corporativismo (empresarial y sindical) y el nuevo poder de la agro-industria. Undurraga a ratos no lo olvida, lo menciona y lo establece como matiz para su propia lectura.

Evidentemente hay una diferencia entre ambos casos. En parte Undurraga utiliza gran parte del texto para explicar los juegos de los actores desde las dictaduras y los gobiernos en democracia, realzando el papel que tuvo, y tiene actualmente, el Peronismo, así como la hegemonía de una derecha neoliberal y conservadora en mantener el orden de la dictadura chilena. Y, sin embargo, creo que una de las diferencias más novedosa aparece cuando este sociólogo arremete con los repertorios de evaluación de ambos grupos empresariales y sus ‘circuitos del capitalismo’ en los últimos tres capítulos (que hayan sido sólo tres de doce capítulos empíricos demuestra a mi entender que la obra queda al debe en una mayor sistematización de éstos repertorios y su peso en la historia que él ha contado). El análisis de la diferencia semántica de cómo fue tratada la crisis financiera global por La Nación y El Mercurio es extraordinario. En Argentina - incluso en un diario conservador - se utilizan repertorios críticos. En Chile, la prensa no habla de capitalismo sino de mercados. Con ello, los mercados florecen como aquellos espacios auto-regulados, sólo técnicamente inteligibles, donde las fallas parecen sólo aparecer cuando hay desacoples entre ofertas y demandas o cuando el Estado regula indebidamente. En Argentina, los mercados son inscritos en un sistema capitalista, donde actores cometen errores, se coluden, especulan y colapsan (como ellos vieron tan nítidamente el 2001). Estas diferencias de evaluación y justificación, tanto en la prensa como en los discursos de políticos y presidentes, son una huella a seguir para observar las estructuras simbólicas de nuestras economías y las narrativas del neoliberalismo. Tomás Undurraga ha dado un primer gran paso en esa dirección. 